\title{
DISTORTION OF PREFERENCES AND THE NASH THEORY OF BARGAINING *
}

\author{
Vincent P. CRAWFORD \\ University of California, San Diego, La Jolla, CA 92093, USA
}

\author{
Ilal R. VARIAN \\ University of Michigan, Ann Arbor, MI 48109, USA
}

Received 4 September 1979

It is shown that in Nash bargaining over division of a single good, when agents are allowed to distort their von Neumann-Morgenstern utility functions into any (weakly) concave form, reporting linear utility functions constitutes a unique dominant-strategy Nash equilibrium.

\section{Introduction}

Nash's (1950) theory and related theories of bargaining are frequently criticized for their lack of empirical content, since their predictions depend on the bargainers' von :Jeumann-Morgenstern utility functions, which are not directly observable. The purpose of this letter is to suggest that an approach recently taken by Kurz (1977, 1978) in a somewhat different context may provide a remedy for this defect. Specifically we observe that agents who engage in a Nash bargaining situation may desire to misrepresent their utility functions. We can then show that a dominant strategy in the preference distortion game is for each agent to report a linear utility function. The resulting Nash bargaining solution is therefore equal division, which is undoubtedly the most often observed bargaining outcome in experimental bargaining situations [cf. Nydegger and Owen (1974)].

\section{The result}

Consider two agents, $u$ and $v$, with von Neumann-Morgenstern utility functions who are playing divide-the-dollar. We distinguish the agents' true utility functions $u_{t}(x)$ and $v_{t}(x)$ from their reported utility functions $u(x)$ and $v(x)$. The only as sumption made concerning the true utility functions is that they are increasing in the money pay-off.

* We are grateful to Mordecai Kurz for helpful discussions. 


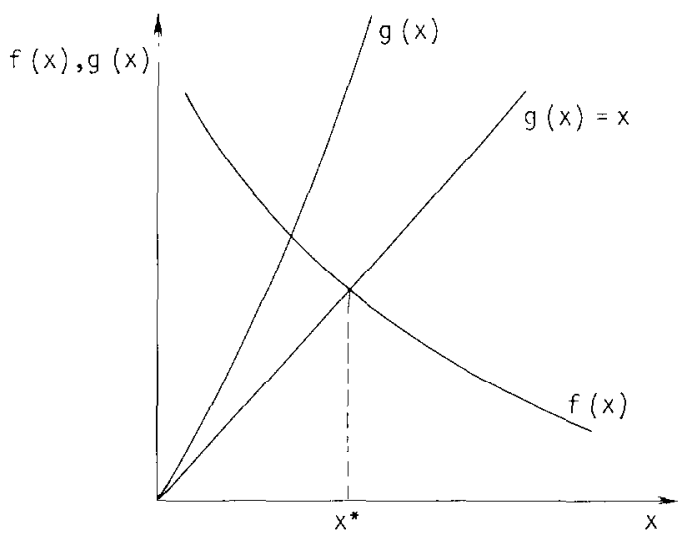

Fig. 1. Nash bargaining solution.

Whatever bargaining process is used we assume that it satisfies Nash's (1950) axioms and therefore results in an allocation that maximizes the product of the two agents' reported utility gains; i.e., it maximizes $(u(x)-u(0))(v(1-x)-v(0))$. Without loss of generality, we will normalize the threat point $(u(0), v(0))$ to be $(0,0)$.

Each agent is aware that the outcome of the bargaining game maximizes the product of the reported utility functions and therefore each agent considers the strategic choice as to which utility function to report. In order for the reported utility functions to be credible, we require that they be differentiable, increasing, and weakly concave functions, normalized so that $u(0)=v(0)=0 .^{1}$

Proposition. Reporting $u(x) \equiv x$ is an essentially unique dominant strategy for agent $u$ in the distortion game.

Proof. Agent $u$ 's pay-off is the solution to

$\max _{0 \leqslant x \leqslant 1} u(x) v(1-x)$,

which has first-order condition

$\frac{u(x)}{u^{\prime}(x)}=\frac{v(1-x)}{v^{\prime}(1-x)}$.

Consider fig. 1, where we have graphed the left-hand and right-hand sides of this

\footnotetext{
${ }^{1}$ Kurz (1977) gives arguments for disallowing risk loving preferences.
} 
equation. The line $f(x)=v(1-x) / v^{\prime}(1-x)$ is downward sloping since

$f^{\prime}(x)=\frac{-v^{\prime}(1-x)^{2}+v(1-x) v^{\prime \prime}(1-x)}{v^{\prime}(1-x)^{2}} \leqslant 0$.

The line $g(x)=u(x) / u^{\prime}(x)$ satisfies $g(0)=0$ and is upward sloping since $g^{\prime}(x)=1-\frac{u(x) u^{\prime \prime}(x)}{u^{\prime}(x)^{2}} \geqslant 0$.

If agent $u$ reports $u(x)=x, g(x)$ will equal $x$ and the resulting outcome will be $x^{*}$. If agent $u$ reports a utility function with $u^{\prime \prime}(x)<0$ at any point then $g^{\prime}(x)<1$ at such a point, implying that $g(x)$ will lie above the line $g(x)=x$. The resulting outcome will therefore be strictly less than $x^{*}$.

Hence it is a dominant strategy for each agent to report $u(x)=v(x)=x$. The resulting Nash bargaining solution is $x^{*}=1 / 2$. Q.E.D.

\section{Remarks}

(1) Our result is related to Kurz's $(1977,1978)$ observation that a linear utility function maximizes each agent's pay-off in an Auman-Kurz $(1977 \mathrm{a}, \mathrm{b})$ power and taxes game. However, Kurz's result rests on the particular form of the pay-off function in the power and taxes game, which in turn depends crucially on the assumption of a continuum of agents.

(2) The proposition could also be proved by appealing to the recent results of Kihlstrom, Roth and Schmeidler (1979), who show that a player's utility at the Nash or the Kalai-Smorodinsky bargaining solution increases as his opponent become more risk averse. This result implies that our Proposition is also valid for the Kalai-Smorodinsky bargaining solution.

(3) Yet another proof of our proposition could be constructed along the lines of Kannai's (1977) observation that among all ordinal representations of an agent's preferences, the 'least concave' representation is most advantageous for him to report in a Nash bargaining context.

(4) Sobel (1979) has recently extended our result to the $n$ good bargaining problem. He shows that any equal income competitive equilibrium for the true utilities is a Nash equilibrium outcome for the utility distortion game.

\section{References}

Aumann, Robert J. and Mordecai Kurz, 1977a, Power and taxes, Econometrica 45, 1137-1161. Aumann, Robert J. and Mordecai Kurz, 1977b, Power and taxes in a multi-commodity economy, Israel Journal of Mathematics 27, 185-234.

Kalai, E. and M. Smorodinsky, 1975, Other solutions to Nash's bargaining problem, Econometrica $43,513-518$. 
Kannai, Yakar, 1977, Concavifiability and construction of concave utility functions, Journal of Mathematical Economics 4, 1-56.

Kihlstrom, Richard E., Alvin E. Roth and David Schmeidler, 1979, Risk aversion and solutions to Nash's bargaining problem, Unpublished mimeo.

Kurz, Mordecai, 1977, Distortion of preferences, income distribution and the case for a linear income tax, Journal of Economic Theory 14, 291-298.

Kurz, Mordecai, 1978, Income distribution and the distortion of preferences: The $l$-commodity case, Technical Report no. 266 (Institute for Mathematical Studies in the Social Sciences, Stanford University, Stanford, CA).

Nash, John, 1950, The bargaining problem, Econometrica 18, 155-162.

Nydegger, R.V. and G. Owen, 1974, Two-person bargaining: An experimental test of the Nash axioms, International Journal of Game Theory 3, 239-250.

Sobel, Joel, 1979, Distortion of utilities and the bargaining problem, Discussion Paper no. 79 29 (University of California, San Diego, La Jolla, CA). 